\title{
Move Analysis of Thesis and Dissertation Abstracts of Local and International Graduate Lecturers
}

\author{
Tara Devina Putri ${ }^{1,{ }^{*}}$ Eri Kurniawan ${ }^{1}$ Wawan Gunawan ${ }^{1}$ Arif Husein Lubis ${ }^{2}$ \\ ${ }^{1}$ English Education Department, Universitas Pendidikan Indonesia \\ ${ }^{2}$ Korean Education Department, Universitas Pendidikan Indonesia \\ ${ }^{*}$ Corresponding author. Email: taradevina@upi.edu
}

\begin{abstract}
Move analysis is one of the genre-based approaches used to analyse the rhetorical structure of academic writing, in which one of them is research abstracts. While rhetorical moves of RA abstract are considerably looked into, the abstract of theses and dissertations is under-explored. The present study aims to investigate the rhetorical moves in abstracts of master's theses and dissertations along with its linguistic realization. It also aims to reveal the similarities and differences between abstracts written for final papers in Indonesian universities and universities in English-speaking countries. The study analyzed abstracts of final papers for master's (S2) and doctoral (S3) degree written by Indonesian local and international graduate lecturers using Hyland's (2000) five-move analysis model as the framework of the study. The findings unfolded that there were some similarities and variations in the move and step occurrences. The use of embedded moves was also found in the study. In terms of language features, similarities in the use of tenses, voice and verb types between abstracts were found. The variations found in the study give a clearer picture to help constructing a more universal guideline for abstract writing in higher education.
\end{abstract}

Keywords: Abstracts, linguistic features, move analysis, rhetorical moves

\section{INTRODUCTION}

In completing a study in many higher learning institutions, either a bachelor, master's, or doctorate degree, students are required to write a thesis or dissertation, in which they have to write an abstract section in English. The abstract plays a crucial role for academic works since its purpose is to attract readers and help them decide on selecting the readings. However, due to the differences in academic writing style between languages, writing an abstract in English is still considered difficult for non-native English speakers. The lack of structural knowledge and linguistic features of abstract makes it challenging for non-native English users to write a well-organized abstract.

Abstract is defined as "an abbreviated, accurate representation of the contents of a document, preferably prepared by its author(s) for publication with it" (Lorés, 2004 , p. 281). Not only as a summary of a text, an abstract also serves as a persuasive tool to attract readers and convince them that the article represented is worth reading. Referring to Hyland (2000, 2004), abstracts are worthy of study because they are significant carriers of a discipline's epistemological and social assumptions.
Research abstracts have especially gained a lot of attention in the recent years since scholars are getting more eager to publish articles in international publications. Hence, a proper structural knowledge about abstracts is becoming a concern. In concern to this problem, Ren and Li (2011) suggested that an effective way to help students cope with the challenges in academic writing might be to make the knowledge of writing explicit to students through genre analysis. For this reason, genre analysis has gained a lot of interest in order to develop a model that can be used to improve the quality of academic writing.

Genre move analysis is first introduced by John M. Swales. Genre, according to Swales (1990), refers to a class of communicative purposes, which is shared and recognized by the members of discourse community. Genre is primarily described in regard to rhetorical structure. Rhetorical structure contains of move and steps. Swales (2004, pp. 228-229) defined move as "a discoursal or rhetorical unit that performs a coherent communicative function in a written or spoken discourse". Move analysis is one of the genre-based approaches used to identify the structure of research articles (Amnuai, 2019a), and is widely used to analyze 
the rhetorical structure of research abstracts. Identifying rhetorical moves and steps may help researchers to fulfill the communicative function of a text.

Swales (1990) and Bhatia (1994) have proposed models for rhetorical structure analysis, but a more recent and elaborate model was proposed by Hyland (2000). Hyland's (2000) model includes five moves: Introduction, Purpose, Methodology, Findings, and Conclusion. Hyland's model was derived from the analysis of 800 abstracts across 8 disciplines (Amnuai, $2019 b$ ), and it covers all the communicative functions of the text units including the Introduction and Purpose move. While Swales' (1990) model was originally proposed for introduction section, this framework focused on the functions of abstract. For the reasons stated above, Hyland's (2000) model is adopted as it is considered as the most suitable model for the present study.

Prior studies on genre move analysis have explored the rhetorical moves in research article (RA) abstracts across disciplines (Darabad, 2016), RA abstracts in local and international journal (Amnuai, 2019a; Saidi \& Cheragi, 2020), and English abstracts written by nonnative English speakers (Al-Khasawneh, 2017; Katic \& Safranj, 2018; Ren \& Li, 2011). Among these studies, the rhetorical moves of RA abstract are considerably looked into, but the abstracts in theses and dissertations is underexplored. Furthermore, from the studies, it can be inferred that the variety of disciplines, types of publication, and the first language of the author might influence the use of a certain structure in abstract writing. However, the possible influence of the educational background of the authors has remained unclear.

The present study aims to investigate the rhetorical moves used in abstracts of master's theses and dissertations, along with the linguistic realization in the abstracts. Hyland's (2000) five-move analysis model is adopted as the framework of the study. The study also aims to reveal the similarities and differences between abstracts written for final papers in Indonesian universities and universities in English-speaking countries in terms of rhetorical structure and linguistic features. Hopefully, the outcome of the study can contribute in constructing a standardized and internationally-accepted model of abstract in final papers such as theses and dissertations.

\section{METHODS}

\subsection{Research Design}

This study employed a qualitative and descriptive comparative approach to achieve the research objectives, that is, to (1) analyze and compare the rhetorical structure and linguistic features of abstracts in theses and dissertations, and (2) to analyze and compare the factors that influence the use of a certain structure and linguistic features. The study adopted Hyland's (2000) five-move model as the guideline for the rhetorical move analysis. The subject of comparison of linguistic realizations were tense, voice and the type of verb.

Hyland's (2000) model includes five moves, namely Introduction, Purpose, Methods, Product, and Conclusion. The Introduction move establishes context of the paper and motivates the research or discussion; the Purpose move indicates purpose, thesis or hypothesis, and outlines the intention behind the paper; the Method move provides information on design, procedures, assumption, approach, and data; the Product move states the main findings or results, the argument, or what was accomplished; and the Conclusion move interprets results beyond scope of paper, draws inferences, points to applications or wider implications (Hyland, 2000, p. 67).

Table 1. Hyland's (2000) five-move model

\begin{tabular}{|c|c|c|c|}
\hline \multicolumn{2}{|c|}{ Move } & \multicolumn{2}{|c|}{ Step } \\
\hline \multirow{4}{*}{ M1 } & \multirow{4}{*}{ Introduction } & S1 & Arguing for topic significance \\
\hline & & $\mathrm{S} 2$ & Making topic generalization \\
\hline & & $\mathrm{S} 3$ & Defining key term(s) \\
\hline & & $\mathrm{S} 4$ & Identifying gap \\
\hline M2 & Purpose & & Stating the research purpose \\
\hline \multirow{3}{*}{ M3 } & \multirow{3}{*}{ Method } & $\mathrm{S} 1$ & $\begin{array}{l}\text { Describing participants/data } \\
\text { sources }\end{array}$ \\
\hline & & $\mathrm{S} 2$ & Describing instrument(s) \\
\hline & & S3 & Describing procedure and context \\
\hline \multirow[t]{2}{*}{ M4 } & \multirow[t]{2}{*}{ Findings } & & Describing the main results \\
\hline & & $\mathrm{S} 1$ & Deducing Conclusion \\
\hline \multirow{3}{*}{ M5 } & \multirow{3}{*}{ Conclusion } & $\mathrm{S} 2$ & $\begin{array}{l}\text { Evaluating the significance of the } \\
\text { research }\end{array}$ \\
\hline & & S3 & Stating limitation \\
\hline & & $\mathrm{S} 4$ & $\begin{array}{l}\text { Presenting recommendation or } \\
\text { implication }\end{array}$ \\
\hline
\end{tabular}

\subsection{Data Source}

The data sources of this study were abstracts of thesis and dissertation written by Indonesian local graduates, Indonesian international graduates and by a mix of both with the total of six abstracts from three participants. The selection of the participants is based on the criteria listed below:

1. The participants are lecturers of a state university in Indonesia of the same discipline (English Department) who have obtained doctoral degree and have written a thesis and dissertation.

2. Participant 1 obtained both their master's and doctoral degree in a university in Australia, Participant 2 obtained their master's and doctoral degree both in universities in Indonesia, and Participant 3 obtained their master's degree in an Indonesian university while the doctoral degree was obtained in a university in Australia.

3. All of the abstracts are written in English except for 
the thesis abstract of Participant 3 which is written in Indonesian.

\subsection{Data Analysis}

The data collection process started with asking for permission to all three participants for their abstracts to be analyzed. Thesis data were identified as T1, T2, and T3, while the dissertation data were identified as D1, D2, and D3. For the abstract pattern analysis, textual approach is used so that the focus will be on the structure and language realization stated in the abstract only. The results refer to the Hyland (2000) model in order to discover the similarities and variations found. The data that have been manually analyzed using the Hyland (2000) model were transferred to Excel to make it easier to find the trends and variations in the abstract pattern. The same process was carried out to find the trends and variations in the linguistic realization.

\section{FINDINGS AND DISCUSSION}

This section intends to address the aims of the study to investigate the rhetorical moves used in theses and dissertations abstracts and the linguistic features (tenses, voice, verb types) in each abstract. The details of move and step occurrences, move patterns, and linguistic realization are described in the subsections below.

\subsection{Move and Step Occurrences}

This subsection describes the rhetorical move and step occurrences in each abstract. The data were acquired by translating the analysis results into percentages. Thus, $\mathrm{T} 1$ refers to thesis of participant number 1 and D1 to dissertation of participant number 1 . The frequency of move occurrence in both datasets is illustrated in Table 2 .

Table 2. Frequency of occurrence of moves in each abstract

\begin{tabular}{lcccccc}
\hline Move & T1 & D1 & T2 & D2 & T3 & D3 \\
\hline M1 & $29 \%$ & $32 \%$ & $17 \%$ & $11 \%$ & $7 \%$ & $21 \%$ \\
M2 & $14 \%$ & $5 \%$ & $22 \%$ & $11 \%$ & $7 \%$ & $3 \%$ \\
M3 & $14 \%$ & $55 \%$ & $17 \%$ & $22 \%$ & $36 \%$ & $16 \%$ \\
M4 & $29 \%$ & $5 \%$ & $33 \%$ & $44 \%$ & $50 \%$ & $37 \%$ \\
M5 & $14 \%$ & $5 \%$ & $11 \%$ & $11 \%$ & - & $24 \%$ \\
\hline
\end{tabular}

Table 2 shows that the five moves in Hyland's (2000) model were used in almost all abstracts except for T3. T3, which is written in Indonesian, did not include the Conclusion move (M5). In a previous study conducted by Amnuai (2019b), the use of M5 could only be found in 1 out of 10 theses written in local university. Since one of the functions of Conclusion move is to show how the study relates to the wider community, he suggested that graduate students face a less competitive pressure in convincing their readers. The main aim of graduate students in writing their theses is to match the criteria set by their institutes and gain acceptance by their thesis committees (Amnuai, 2019b).

The number of occurrences shown in Table 2 also reveals that most of the abstracts emphasized the use of Move 4, which is Findings, except for T1 and D1. The large number of occurrence of Move 4 is supported by previous studies (Al-Khasawneh, 2017; Amnuai, 2019a, 2019b; Ren \& Li, 2011; Saidi \& Cheragi, 2020) where the Findings or Product move was considered obligatory. $\mathrm{T} 1 \mathrm{had}$ an equal share of occurrence of the Introduction and Findings move. As for D1, the abstract emphasized the Method move with the occurrence of 55 percent. This frequency of occurrence was due to the use of several approaches and the novelty of the method used for the author's study. The moves with the lowest occurrence average were M2 (Purpose) with an average of 11 percent and M5 (Conclusion) with 10 percent.

Participant 1, in their thesis abstract, emphasized the Findings and Introduction move both with a percentage of 29 percent. As for the dissertation, Participant 1 emphasized the Method move $(55 \%)$, followed by Introduction $(32 \%)$. The trend found in the thesis and dissertation abstract of Participant 1 is that other than the two moves with the biggest number of occurrences, the rest three moves always had the same percentage of occurrence.

Participant 2 emphasized the use of M4 - Findings in both their thesis and dissertation abstract. While the second most used move in the thesis abstract is M2 (Purpose), M3 or the Method move was the second focus of the dissertation abstract. The occurrence of the rest of the moves were quite balanced.

Participant 3 also emphasized the Findings move in their thesis and dissertation abstract. An interesting finding is that while the thesis abstract did not include the Conclusion move at all, Conclusion is the second move with the biggest occurrence in the dissertation. This was influenced by the research topic of the dissertation which included a suggestion to put the findings of the study into practice.

Table 3 presents the frequency of occurrences of steps used in the study. Only the step manifestation of Move 1, Move 3 and Move 5 were further analysed, since Move 2 and Move 4 do not have any step. Based on the table, Step 2 - Evaluating the significance of the research and Step 3 - Stating limitation of Move 5 had no occurrence in any abstract. In contrast, Step 2 of Move 1 - Making topic generalization occurred in all abstracts. A more varied results were found in the step occurrence of each abstracts of the participants. 
Participant 1 never included Step 3 and Step 4 of Move 1, also Step 1 of Move 5 in both their thesis and dissertation abstract. Only four steps were manifested in the thesis abstract with an equal number of occurrences. As for the dissertations, more steps were added in the abstract, even though the occurrence percentage was not high.

Table 3. Frequency of occurrence of steps

\begin{tabular}{cccccccc}
\hline Move & Step & T1 & D1 & T2 & D2 & T3 & D3 \\
\hline \multirow{4}{*}{ M1 } & S1 & $25 \%$ & $5 \%$ & - & - & - & $13 \%$ \\
& S2 & $25 \%$ & $30 \%$ & $18 \%$ & $25 \%$ & $14 \%$ & $4 \%$ \\
& S3 & - & - & - & - & - & $13 \%$ \\
& S4 & - & - & $9 \%$ & - & - & $4 \%$ \\
\multirow{4}{*}{ M3 } & S1 & - & $5 \%$ & $9 \%$ & - & $29 \%$ & - \\
& S2 & - & $5 \%$ & $18 \%$ & $50 \%$ & - & $17 \%$ \\
& S3 & $25 \%$ & $50 \%$ & $9 \%$ & - & $57 \%$ & $9 \%$ \\
& S1 & - & - & - & $25 \%$ & - & $22 \%$ \\
& S2 & - & - & - & - & - & - \\
& S3 & - & - & - & - & - & - \\
& S4 & $25 \%$ & $5 \%$ & $36 \%$ & - & - & $17 \%$ \\
\hline
\end{tabular}

Step 1 and Step 3 of Move 1 did not occur in any abstract of Participant 2. In contrast to Participant 1, the number of steps used in the dissertation abstract was less than the steps used in the thesis abstract. The steps used in the thesis abstract were more varied.

As for Participant 3, there was a big difference in the step occurrence between the thesis and dissertation abstract. While the thesis abstracts only used three steps, namely Step 2 of Move 1 along with Step 1 and Step 3 of Move 3, eight out of eleven steps were manifested in the dissertation abstract. Other than the two steps of Move 5 that never occurred, Step 1 of Move 3 was also not found in the dissertation abstract.

\subsection{Move Pattern}

This subsection presents the rhetorical move pattern found in the present study. The details regarding the move patterns are presented in Table 4.

Table 4. Move patterns found in each abstract

\begin{tabular}{ll}
\hline Abstract & Pattern \\
\hline T1 & I $-\mathrm{P}(\mathrm{M})-\mathrm{F}-\mathrm{C}$ \\
D1 & $\mathrm{I}-\mathrm{P}-\mathrm{M}-\mathrm{F}-\mathrm{C}$ \\
T2 & $\mathrm{I}-\mathrm{P}-\mathrm{M}-\mathrm{F}-\mathrm{C}$ \\
D2 & $\mathrm{I}-\mathrm{P}-\mathrm{F}(\mathrm{M})-\mathrm{C}$ \\
T3 & $\mathrm{I}-\mathrm{P}-\mathrm{M}-\mathrm{F}$ \\
D3 & $\mathrm{I}-\mathrm{P}-\mathrm{M}-\mathrm{F}-\mathrm{C}$ \\
\hline
\end{tabular}

In general, regardless of the master's and doctoral educational background, the move patterns found in the abstracts were written sequentially from Move 1 (Introduction) to Move 5 (Conclusion).

One interesting point was discovered from the patterns, that is, the use of combinations of two moves together or embedded moves. The embedded moves found in the study were namely Purpose + Method and Findings + Method. The following excerpts shows the manifestation of the embedded moves.

\section{Example 1: Purpose + Method}

Using Bhabha's notion of the third space as its major theoretical framework and narrative inquiry as its main methodological tool, it specifically aims to explore processes of identity formation in the 'new space'. (T1)

Example 2: Findings + Method

Employing structuralism approach and system formal analysis form Bordwell and Thompson (2008), it is found that textual structure and narrative strategies are ambivalent because they position child characters as subjects, but only under certain conditions: the absence or without involvement of adult characters, in open space, and group-oriented. (D2)

Example 3: Findings + Method

Further analysis using Foucault theory of power and governmentality (1995) found that although literacy is the child's potential skill to shift adult's dominant power and negotiating positions take place temporarily, the child character's subjectivity is generally constructed through discipline in social practices. (D2)

From the embedded moves found in the study, it can be seen that Move 3 or Method were often combined or embedded to another move. Similar finding was found in a prior study by Amnuai (2019b). This trend indicates that the authors did not center their attention on writing the methods, or that the methods and approaches used in the study were already well-known so that further explanation is not needed.

\subsection{Linguistic Features}

This subsection discusses the details concerning the language features, such as tenses, voice and types of verb. This will correlate to the second aim of the present study to find out the linguistic realization in the abstracts. Table 5 presents the use of tense in each abstract.

Tenses were not found in T3 since it is written in Indonesian. Overall, the most used tenses in the abstracts

Table 5. The use of tense in each abstract

\begin{tabular}{lccccc}
\hline Tense & T1 & D1 & T2 & D2 & T3 \\
Present & $50 \%$ & $73 \%$ & $94 \%$ & $86 \%$ & - \\
Tense & $27 \%$ & $6 \%$ & $14 \%$ & - \\
Past Tense & $50 \%$ & $2 \%$ & \\
\hline
\end{tabular}

Table 6. The use of voice in each abstract

\begin{tabular}{lcccccc}
\hline Voice & T1 & D1 & T2 & D2 & T3 & D3 \\
\hline Active & $67 \%$ & $68 \%$ & $100 \%$ & $71 \%$ & $43 \%$ & $74 \%$ \\
Voice & & & & & & \\
$\begin{array}{l}\text { Passive } \\
\text { Voice }\end{array}$ & $33 \%$ & $32 \%$ & $0 \%$ & $29 \%$ & $57 \%$ & $26 \%$ \\
\hline
\end{tabular}


were present tense. The difference of the percentage of usage was significant. Besides $\mathrm{T} 1$, the present tense usage in the abstracts exceeded 70 percent. The use of present and past tense in T1 was balanced.

The voice usage displayed in Table 6 shows an interesting result. All of the abstracts written in English (T1, D1, T2, D2, D3) used active voice more than passive voice, with a percentage of more than 65 percent. Abstract with a full use of active voice was also found, namely in $\mathrm{T} 2$. However, the abstract written in Indonesian (T3) mainly used passive voice. This indicates that regardless of the educational background that is related to English, the habit and style when writing using a certain language remains. Passive voice is used more frequently by Indonesians because of cultural difference where Indonesian tends to put the subject at the end of the sentence (Apandi \& Islami, 2018).

Table 7 provides the details on the type of verbs used in the abstracts. The verb types that are focused on the present study are action verb, linking verb, and helping verb. It can be seen from the table that action verb was the most used type in almost all abstracts, except for D1. D1 mainly used helping verb in the writing.

Table 7. The type of verb used in each abstract

\begin{tabular}{lcccccc}
\hline Verb Type & T1 & D1 & T2 & D2 & T3 & D3 \\
\hline Action Verb & $83 \%$ & $32 \%$ & $67 \%$ & $43 \%$ & $71 \%$ & $53 \%$ \\
Linking & $0 \%$ & $5 \%$ & $22 \%$ & $29 \%$ & $29 \%$ & $16 \%$ \\
Verb & & & & & & \\
Helping & $17 \%$ & $64 \%$ & $11 \%$ & $29 \%$ & $0 \%$ & $32 \%$ \\
Verb & & & &
\end{tabular}

\section{CONCLUSION}

This study has compared the rhetorical structure and linguistic realization of abstracts in theses and dissertations written by Indonesian local and international graduate lecturers. Overall, the findings reveal many similarities between the abstracts. The five moves in Hyland's (2000) model occurred in all abstracts written in English. Move 4 - Findings was the most manifested move in all abstracts. However, a more varied result was found in the step occurrence level since each participant focused on different steps in each abstract. The patterns of move in the abstracts were all sequential from Move 1 - Introduction to Move 5 - Conclusion regardless of the master's and doctoral educational background. Regarding the linguistic realization, no significant difference was found in all abstracts.

Despite the small scale of data used in the present study, the results of the present study could enrich the existing literature in the field of academic writing, especially in thesis and dissertation writing. To give a clearer picture of the manifestations of rhetorical and grammatical features of abstracts in theses and dissertations, the use of a larger data set is suggested.

\section{ACKNOWLEDGMENTS}

This study was supported by a grant from the Research and Community Service Unit, Indonesia University of Education. The authors would like to express appreciation for all the support provided.

\section{REFERENCES}

Al-Khasawneh, F. M. (2017). A genre analysis of research article abstracts written by native and nonnative speakers of English. Journal of Applied Linguistics and Language Research, 4(1), 1-13.

Amnuai, W. (2019a). Analyses of rhetorical moves and linguistic realizations in accounting research article abstracts published in international and Thai-based journals. SAGE Open, 9(1). https://doi.org/10.1177/2158244018822384

Amnuai, W. (2019b). Rhetorical move structures and linguistic realizations of abstracts in ICT research articles and master's theses. SAGE Open, 8(1), 157184.

https://so05.tcithaijo.org/index.php/MFUconnexion/article/view/2 41189

Apandi \& Islami, F. N. (2018). Translation analysis on passive voice from Indonesian into English found in "Gua Sunyaragi" book. Academic Journal Perspective: Education, Language, and Literature, 6(2), $110-118$ https://doi.org/10.33603/perspective.v6i2.1576

Bhatia, V. K. (1994). Analyzing genre: Language use in professional setting. London: Longman.

Darabad, A. M. (2016). Move analysis of research article abstracts: A cross-disciplinary study. International Journal of Linguistics, 8(2), 125-140. https://doi.org/10.5296/ijl.v8i2.9379

Hyland, K. (2000). Disciplinary discourses: Social Interactions in academic writing. Longman.

Hyland, K. (2004). Disciplinary discourses: Social interactions in academic writing. The University of Michigan Press.

Katic, M., \& Safranj, J. (2018). An analysis of dissertation abstracts written by non-native English speakers at a Serbian university: Differences and similarities across disciplines. In M. Chitez, C. Doroholschi, O. Kruse, Ł. Salski \& D. Tucan (Eds.), University writing in Central and Eastern Europe: Tradition, transition, and innovation (pp. 231-248). Springer, Cham https://doi.org//10.1007/978-3-319-95198-0_16

Lorés, R. (2004). On RA abstracts: From rhetorical structure to thematic organization. English for 
Specific Purposes, 23(3), 280-302.

https://doi.org/10.1016/j.esp.2003.06.001

Ren, H., \& Li, Y. (2011). A comparison study on the rhetorical moves of abstracts in published research articles and master's foreign-language theses. English Language Teaching, 4(1), 162. https://doi.org/10.5539/elt.v4n1p162

Saidi, M., \& Cheragi, F. (2020). Global journal of foreign abstracts: Local versus international journal. Global Journal of Foreign Language Teaching, 10(2), 111119. https://doi.org/10.18844/gjflt.v10i2.4699

Swales, J. M. (1990). Genre analysis: English in academic and research settings. Cambridge University Press.

Swales, J. M. (2004). Research genres: Explorations and applications. Cambridge University Press. 